\title{
Effect of Dibutyryl Adenosine 3', 5'-Cyclic Monophosphate on Several Metabolic Systems in Sea Urchin Eggs
}

\author{
Ikuo Yasumasu, Akiya Hino and *Kouichi Asami \\ Department of Biology, School of Education, Waseda University, Nishiwaseda, \\ Shinjuku-ku, Tokyo 160, and *Division of Biology, National Institute of \\ Radiological Sciences, Anagawa, Chiba 280, Japan
}

\begin{abstract}
Effects of dibutyryl adenosine 3', 5'-cyclic monophosphate (db-cAMP) on glycolysis, oxygen uptake and protein synthesis were investigated in unfertilized sea urchin eggs to examine the possible role of adenosine $3^{\prime}, 5$ '-cyclic monophosphate in the activation of cellular functions upon fertilization. Treatment of unfertilized eggs with 1 to $5 \mathrm{mM}$ of db-cAMP caused activation of the glycolytic system but exerted no effect on oxygen uptake and protein synthesis. The influx of $\mathrm{Ca}^{2+}$ into the eggs, having been demonstrated upon fertilization, was not observed in unfertilized eggs when the eggs were treated with cAMP.
\end{abstract}

Adenosine 3', 5'-cyclic monophosphate (cAMP) has been reported to increase in sea urchin eggs after fertilization $(7,17)$. Since the compound is known to regulate many cell functions (10), activation of some metabolic systems upon fertilization may be expected from an increase in the intracellular concentration of the compound. Therefore, it is necessary to distinguish the enzyme system or systems which can be activated by cAMP in unfertilized sea urchin eggs. To determine the action of cAMP on cell functions, dibutyryl adenosine 3', 5'-cyclic monophosphate (bd-cAMP), an analogue of cAMP, is commonly used to overcome the low permeability of cell membranes to cAMP. This paper describes the effects of db-cAMP on several functions in unfertilized eggs.

\section{MATERIALS AND METHODS}

Mature eggs of the sea urchin Anthocidaris crassispina were handled as described previously (16). Unfertilized eggs were suspended and kept at $23^{\circ} \mathrm{C}$ for 10 or $20 \mathrm{~min}$ in filtered sea water containing db-cAMP at concentrations from 0.01 to $50 \mathrm{mM}$. Fertilized eggs were allowed to develop at $23^{\circ} \mathrm{C}$ with gentle stirring. The intracellular concentration of db-cAMP was intended to be determined after incubation. However, it was unsuccessful, because there was too much extracellular db-cAMP in the sea water compared with that expected in the eggs.

All enzymes, NADP and NADH used for assays, as well as cAMP and db-cAMP were the products of Boehringer Mannheim Co., Germany. ${ }^{14} \mathrm{C}$-Leucine $(342 \mathrm{mCi} / \mathrm{mmole})$ was purchased from the Radiochemical Center, Amersham, England. ${ }^{45} \mathrm{CaCl}_{2}$ was obtained from the International Chemical and Nuclear Corporation, England.

Estimation of glycolytic intermediates, adenine nucleotides and inorganic phosphate. The eggs kept in sea water containing db-cAMP for 10 or 20 min were collected by centrifugation 
at 5,000 $\mathrm{g}$ for $3 \mathrm{~min}$ in the cold. The egg pellet was mixed with an equal volume of $10 \%$ perchloric acid and homogenized with the aid of a Teflon pestle-glass homogenizer in an ice bath. After dilution of the homogenate with distilled water to reduce the perchloric acid concentration to $3 \%$, the homogenate was centrifuged at $10,000 \mathrm{~g}$ for $30 \mathrm{~min}$ at $4{ }^{\circ} \mathrm{C}$. The precipitate was utilized for the Biuret determination. The supernatant was mixed with $1 / 10$ the volume of $1 \mathrm{M}$ triethanolamine hydrochloride, and neutralized to $\mathrm{pH} 6.8$ with $5 \mathrm{M}$ $\mathrm{K}_{2} \mathrm{CO}_{3}$. The neutralized aliquot was centrifuged at $100,000 \mathrm{~g}$ for 1 hour, and the supernatant was analyzed for intermediates of glycolysis, adenine nucleotides and inorganic phosphate, as described previously (16).

$\mathrm{Ca}^{2+}$ influx into eggs. Sea urchin eggs either fertilized or unfertilized were immersed in sea water containing ${ }^{45} \mathrm{CaCl}_{2}$ (about $15,000 \mathrm{cpm} / \mathrm{ml}$ ) and $0.1 \mathrm{~g} / \mathrm{ml}$ blue dextran (incubation mixture). The eggs were collected with centrifugation on a hand driven centrifuge every 5 min, and washed twice with ice-cold sea water as soon as possible. To the egg pellet thus obtained (about $0.05 \mathrm{ml}$ ) was added distilled water to make $2 \mathrm{ml}$ of egg suspension. Absorbance at $650 \mathrm{~nm}$ which was due to blue dextran on the egg pellet of the egg suspension was estimated. Whole egg suspension was dried on a planchette, and the radioactivity was estimated on a gas flow counter (Nihon Musen Co., Japan). In the extracellular space in the egg pellet, possible contamination of ${ }^{45} \mathrm{Ca}$ would remain even after the eggs were washed twice with sea water. However, the concentration of blue dextran, which would not penetrate into the eggs, was very low in the egg pellet finally obtained. This suggested that blue dextran in the extracellular space was eliminated by washing eggs twice with sea water. Hence, the possible contamination of ${ }^{45} \mathrm{Ca}$ in the extracellular space is probably negligible.

Measurement of oxygen uptake. The oxygen uptake of sea urchin eggs was estimated polarographically. About $5 \times 10^{5}$ eggs were introduced into a closed vessel containing $3 \mathrm{ml}$ sea water at $23^{\circ} \mathrm{C}$, and the oxygen consumption was recorded with the aid of the Beckman oxygen electrode. The oxygen content of sea water was calculated to be $0.47 \mu \mathrm{g}$ atom of $\mathrm{O} / \mathrm{ml}$ at $23^{\circ} \mathrm{C}$, based on the oxygen content of sea water at $25^{\circ} \mathrm{C}(8)$ and $18^{\circ} \mathrm{C}(13)$ and on the oxygen content of the mixture for mitochondrial respiration (2).

Estimation of protein synthesis. The rate of protein synthesis was determined from the degree of ${ }^{14} \mathrm{C}$-leucine incorporation into the protein of the eggs. About $0.2 \mathrm{ml}$ of eggs was incubated at $20^{\circ} \mathrm{C}$ for $20 \mathrm{~min}$ in $2 \mathrm{ml}$ of sea water containing $0.1 \mu \mathrm{Ci} / \mathrm{ml}$ of ${ }^{14} \mathrm{C}$-leucine with or without db-cAMP. Incubation was initiated by adding ${ }^{14} \mathrm{C}$-leucine into the egg suspension, and after $20 \mathrm{~min}$ of incubation $1 \mathrm{ml}$ of $10 \%$ trichloroacetic acid was poured into the suspension. The eggs were homogenized in an ice bath and centrifuged at 2,000 rpm for $5 \mathrm{~min}$. The precipitate was washed twice with $5 \%$ trichloroacetic acid, heated at $90^{\circ} \mathrm{C}$ for $20 \mathrm{~min}$ and washed again with $5 \%$ trichloroacetic acid. After washing with $95 \%$ ethanol saturated with sodium acetate, the precipitate was washed twice with ethanol-ether $(3: 1, \mathrm{v} / \mathrm{v})$ and dissolved with concentrated formic acid. An aliquot was dried on a planchette, and its radioactivity was measured on a gas flow counter. Protein was determined according to Lowry et al. (5).

\section{RESULTS}

Effects on glycolysis. Elevation of fertilization membrane was not observed when unfertilized eggs were immersed into sea water containing db-cAMP, as well as cAMP at concentrations between $1 \mathrm{mM}$ and $100 \mathrm{mM}$. On the other hand, the glycolytic system in unfertilized eggs was activated with db-cAMP. Table 1 shows the contents of glycolytic intermediates, adenine nucleotides and inorganic phosphate in unfertilized eggs incubated with db-cAMP for $10 \mathrm{~min}$. The contents of these compounds at 10 min after insemination are also shown. The data agree closely with those in the 
previous paper (16); glucose 1-phosphate was not detected. The contents of glucose 6-phosphate, fructose 6-phosphate and pyruvate increased significantly in fertilized eggs, while a slight decrease in lactate, as well as ATP was observed.

TABLE 1. CONTENTS OF GLYCOLYTIC INTERMEdiates AND ADENINE NUCLEOTIDES IN Anthocidaris EGGS TREATED WITH db-cAMP

\begin{tabular}{lcccccc}
\hline & \multicolumn{5}{c}{ Concentration of db-cAMP (mM) } \\
\cline { 2 - 6 } & \multicolumn{7}{c}{ Unfertilized eggs $(10$ min } & incubation) & Fertilized eggs \\
G6P & $9.7(1.1)$ & $15.7(7.1)$ & $34.9(10.3)$ & $25.8(4.1)$ & $19.1(2.9)$ & $45.9(2.1)$ \\
F6P & $3.0(0.7)$ & $4.4(1.7)$ & $11.9(7.8)$ & $8.2(0.4)$ & $7.2(10.5)$ & $10.4(1.1)$ \\
FDP & $3.2(1.5)$ & $6.8(3.2)$ & $31.4(11.9)$ & $52.4(11.4)$ & $50.6(6.7)$ & $6.8(0.8)$ \\
DHAP & $4.8(1.0)$ & $8.8(4.3)$ & $32.3(14.1)$ & $49.5(9.6)$ & $50.7(8.6)$ & $5.9(0.7)$ \\
GA3P & $3.9(1.4)$ & $4.9(1.2)$ & $10.9(6.1)$ & $28.2(7.1)$ & $24.2(4.3)$ & $2.8(0.6)$ \\
3PG & $9.9(3.6)$ & $8.2(3.5)$ & $16.1(7.9)$ & $30.1(9.5)$ & $26.4(4.1)$ & $8.7(0.4)$ \\
2PG & $3.6(0.7)$ & $6.3(0.6)$ & $11.3(8.6)$ & $14.9(6.2)$ & $14.3(6.3)$ & $3.9(1.0)$ \\
PEP & $24.2(2.8)$ & $24.0(3.9)$ & $20.5(8.9)$ & $15.2(2.0)$ & $15.6(1.1)$ & $24.0(3.9)$ \\
Pyr & $8.3(1.0)$ & $8.0(1.1)$ & $28.0(9.7)$ & $27.1(6.2)$ & $25.4(2.9)$ & $27.4(7.1)$ \\
Lac & $266.4(48.0)$ & $260.8(51.5)$ & $894.0(197.0)$ & $815.0(99.3)$ & $787.1(62.0)$ & $241.3(42.4)$ \\
ATP $a$ & $1.69(0.19)$ & $1.72(0.15)$ & $1.73(0.42)$ & $1.70(0.25)$ & $1.88(0.14)$ & $1.60(0.25)$ \\
ADP & $130.4(24.1)$ & $135.3(29.2)$ & $140.8(31.1)$ & $126.8(19.2)$ & $141.5(19.2)$ & $179.9(35.4)$ \\
AMP & $70.5(18.5)$ & $71.8(20.3)$ & $88.4(26.2)$ & $65.8(9.7)$ & $71.3(10.1)$ & $89.4(18.2)$ \\
Pi $a$ & $40.3(13.0)$ & $37.6(8.2)$ & $45.7(19.1)$ & $42.6(11.5)$ & $43.0(9.8)$ & $40.3(21.0)$ \\
\hline
\end{tabular}

All values are expressed as $\mathrm{n}$ moles $/ 10^{6}$ eggs except for ATP and $\mathrm{Pi}(a)$ which are expressed as $\mu$ moles $/ 10^{6}$ eggs. The values shown are the means of three independent experiments with the standard error of the mean in parentheses. Fertilized eggs were obtained 10 minutes after fertilization. Abbreviations: G6P, glucose 6-phosphate; F6P, fructose 6-phosphate; FDP, fructose 1,6-bisphosphate; DHAP, dihydroxyacetone phosphate; GA3P, glyceraldehyde 3-phosphate; 3PG, 3-phosphoglycerate; 2PG, 2-phosphoglycerate; PEP, phosphoenolpyruvate; Pyr, pyruvate; Lac, lactate; Pi, inorganic phosphate.

When unfertilized eggs were treated with db-cAMP, similar changes were observed in the contents of these compounds to those after fertilization. However, there were also considerable differences between fertilization and db-cAMP treatment. Lactate content in db-cAMP-treated unfertilized eggs increased obviously, in contrast to its decrease after fertilization. During the incubation of unfertilized eggs with db-cAMP, the level of glucose 6-phosphate as well as fructose 6-phosphate increased considerably. The fructose 1, 6-bisphosphate level was also significantly higher in the dbcAMP-treated unfertilized eggs than in the fertilized eggs. As already shown in the previous paper, fructose bisphosphate in eggs increases after ferilization with about 10 min lag time (16). The fructose bisphosphate content of the same batches of eggs as those in Table 1 was also determined at $20 \mathrm{~min}$ after fertilization and found to be $14.4 \pm 4.4 \mathrm{nmoles} / 10^{6}$ eggs. Thus, the db-cAMP at more than $5 \mathrm{mM}$ has a more potent effect than fertilization on the accumulation of fructose bisphosphate. The content of adenine nucleotides was found to remain unchanged in unfertilized eggs even after db-cAMP treatment, whereas considerable changes were observed after fertilization.

The concentration of db-cAMP shown in Table 1 seems to be higher than that commonly used for mammalian cells. However, the level of glycolytic intermediates in eggs treated with either 0.01 or $0.1 \mathrm{mM}$ db-cAMP was almost the same as in the 
TABLE 2. EFFECT OF CAMP, AMP AND SODIUM BUTYRATE TREATMENT ON THE CONTENT OF THE GLYCOLYTIC INTERMEDIATES IN UNFERTILIZED EGGS

\begin{tabular}{|c|c|c|c|c|c|c|}
\hline & \multicolumn{4}{|c|}{ Experiment 1} & \multicolumn{2}{|c|}{ Experiment 2} \\
\hline & $\begin{array}{c}\text { No } \\
\text { treatment }\end{array}$ & $\begin{array}{l}10 \mathrm{mM} \\
\mathrm{cAMP}\end{array}$ & $\begin{array}{l}40 \mathrm{mM} \\
\mathrm{cAMP}\end{array}$ & $\begin{array}{c}10 \mathrm{mM} \\
\text { AMP }\end{array}$ & $\begin{array}{l}\text { No } \\
\text { treatment }\end{array}$ & $\begin{array}{c}10 \mathrm{mM} \\
\text { Butyrate }\end{array}$ \\
\hline G6P & 6.9 & 6.4 & 6.9 & 6.0 & 7.7 & 7.0 \\
\hline F6P & 2.6 & 2.2 & 2.7 & 2.3 & 3.4 & 3.5 \\
\hline FDP & 3.3 & 3.0 & 5.9 & 3.2 & 3.0 & 3.1 \\
\hline DHAP & 4.9 & 5.0 & 6.2 & 5.1 & 5.2 & 4.6 \\
\hline GA3P & 4.0 & 4.1 & 4.6 & 3.6 & 3.6 & 3.8 \\
\hline $3 P G$ & 7.7 & 8.6 & 9.7 & 7.3 & 9.7 & 10.2 \\
\hline $2 \mathrm{PG}$ & 4.0 & 4.0 & 4.2 & 3.9 & 3.0 & 2.7 \\
\hline PEP & 23.4 & 23.7 & 23.7 & 24.1 & 25.0 & 23.0 \\
\hline Pyr & 7.6 & 9.0 & 8.1 & 6.9 & 6.7 & 8.9 \\
\hline Lac & 262.5 & 259.3 & 276.6 & 261.4 & 266.3 & 289.5 \\
\hline
\end{tabular}

For abbreviations, see the legend of Table 1.

nontreated control. Only the fructose 1, 6-bisphosphate level in eggs treated with $0.1 \mathrm{mM}$ bd-cAMP was slightly elevated $\left(5.9 \pm 0.6 \mathrm{nmoles} / 10^{6}\right.$ eggs $)$.

The activation of glycolysis was specific for db-cAMP, since neither AMP nor sodium butyrate had an effect on the level of the glycolytic intermediates (Table 2). The effects of cAMP are also shown in Table 2. Although $10 \mathrm{mM}$ cAMP was not effective, $40 \mathrm{mM}$ cAMP induced a slight elevation of fructose 1, 6-bisphosphate level in eggs. Therefore, db-cAMP or cAMP penetrates into the egg resulting in activation of glycolysis. Thus, the difference between db-cAMP and cAMP is due to a difference of their permeability.

The contents of these compounds were also determined after 20 min of incubation with db-cAMP. Prolonged incubation results in a decrease in the content of hexose phosphate and an increase in lactate when compared to incubation for $10 \mathrm{~min}$. The levels of 3-carbon compounds were in between (data not shown).

Effects on Ca distribution. Activation of glycolysis in unfertilized eggs by db-cAMP is due to the action of the compound penetrating into the eggs. It is, however, possible that db-cAMP causes an increase of $\mathrm{Ca}^{2+}$ influx into eggs resulting in activation of glycolysis, since $\mathrm{Ca}^{2+}$ as well as cAMP is an effector of glycolysis $(3,4,9,12)$, and since activation of cation flux by cAMP through activation of protein kinase was reported on other membranes $(11,14)$.

The effects of db-cAMP were examined on eggs suspended in $1 \mathrm{M}$ glycerol, where an elevation of intracellular free $\mathrm{Ca}$ ion due to $\mathrm{Ca}$ influx would not occur. The same pattern of changes was observed as that in db-cAMP containing sea water (data not shown). Moreover, $\mathrm{Ca}^{2+}$ influx into eggs was not found when they were immersed in db-cAMP containing sea water (Fig. 1).

Effects on oxygen uptake. The oxygen uptake of either fertilized or unfertilized eggs was hardly stimulated with db-cAMP (Fig. 2). Activation of glycolysis without activation of respiration may result in the accumulation of pyruvate and lactate in eggs (Table 1).

Effects on protein synthesis. Besides the activation of both glycolysis and respiration, an increase in protein synthesis is one of the important cell functions stimulated upon fertilization. However, protein synthesis was not enhanced in either unfertilized or fertilized eggs immersed in 0.1 to $10 \mathrm{mM} \mathrm{db-cAMP}$ (Table 3). Hence, an increase 


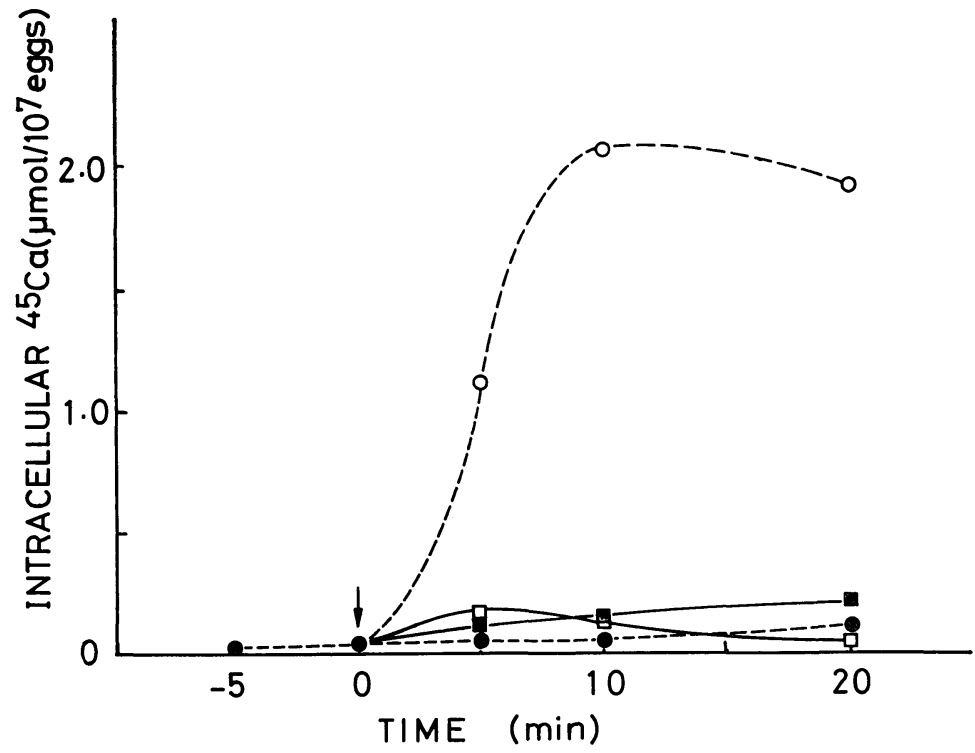

Fig. 1. Uptake of ${ }^{45} \mathrm{Ca}$ into eggs incubated with cyclic adenine nucleotides. At time 0 , sperm $(\bigcirc), 50 \mathrm{mM}$ db-cAMP ( $\square$ ) or $100 \mathrm{mM}$ cAMP ( $\square$ ) was added to the egg suspension. $\bullet$, Unfertilized eggs.

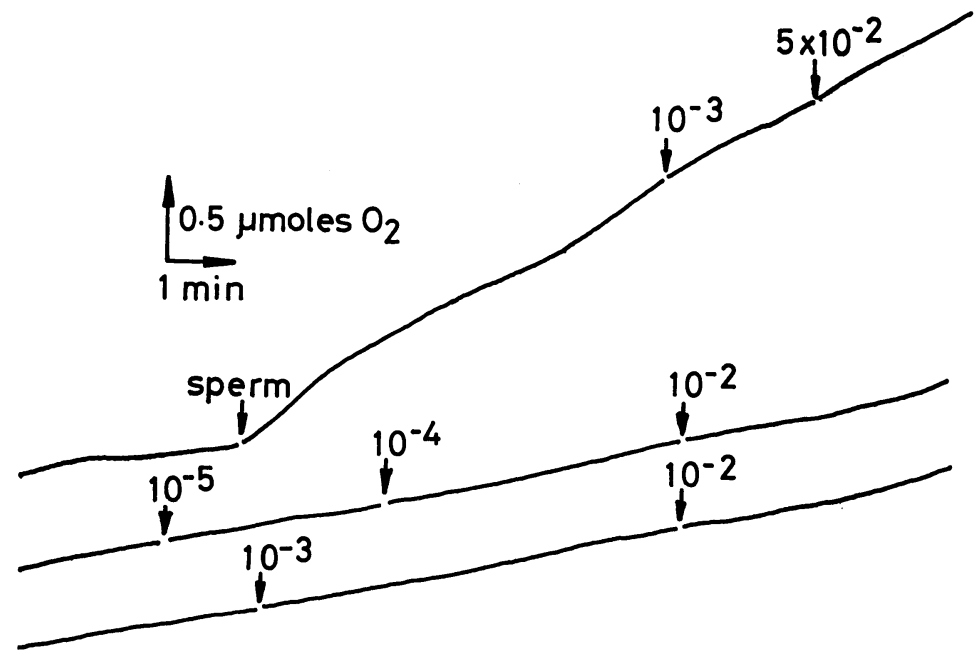

Fig. 2. Effect of db-cAMP on oxygen consumption of eggs. At the times shown by the arrows, db-cAMP was added at the indicated concentrations. 
TABLE 3. PROTEIN SYNTHESIS OF SEA URCHIN EGGS INCUBATED WITH VARYING CONCENTRATIONS OF db-CAMP

\begin{tabular}{ccc}
\hline \multirow{2}{*}{$\begin{array}{c}\text { Concentration } \\
\text { of db-cAMP }(\mathrm{M})\end{array}$} & \multicolumn{2}{c}{${ }^{14}$ C-leucine incorporation $(\mathrm{cpm} / \mathrm{mg}$ protein) } \\
\cline { 2 - 3 } & Unfertilized eggs & Fertilized eggs \\
\hline 0 & 541.6 & 5122 \\
$10^{-4}$ & 638.5 & 5311 \\
$10^{-3}$ & 664.4 & 5196 \\
$10^{-2}$ & 505.2 & 4732 \\
\hline
\end{tabular}

in cAMP content after fertilization appears not related to the activation of protein synthesis $(7,17)$.

\section{DISCUSSION}

The mass action ratios of each glycolytic reaction step were calculated from the data shown in Table 1 to examine the mechanism of activation of glycolysis by dbcAMP (Table 4) (16). The NAD:NADH ratios were calculated on the assumption that the lactate dehydrogenase step was in equilibrium (16). The ratios in unfertilized eggs showed no change with 1 to $50 \mathrm{mM}$ of db-cAMP in contrast to fertilized eggs. This reflects the fact that db-cAMP failed to activate respiration which was activated by fertilization (Fig. 2). For calculation of the mass action ratios for the phosphorylase step, glucose 6-phosphate concentration was used instead of glucose 1-phosphate.

TABLE 4. Mass aCtion RATIOS OF GLyCOLYTIC REACTIONS IN SEA URCHIN EGGS TREATED WITH db-cAMP FOR 10 MINUTES

\begin{tabular}{|c|c|c|c|}
\hline & \multirow{2}{*}{\multicolumn{2}{|c|}{$\begin{array}{c}\text { Unfertilized eggs } \\
\text { db-cAMP concentration }\end{array}$}} & \multirow{2}{*}{$\begin{array}{l}\text { Fertilized eggs } \\
\text { (10 minutes after } \\
\text { fertilization) }\end{array}$} \\
\hline & & & \\
\hline$\frac{[\mathrm{G} 6 \mathrm{P}]}{[\mathrm{Pi}]} \times 10^{4}$ & 2.4 & 6.1 & 11.2 \\
\hline $\begin{array}{l}{[\mathrm{F} 6 \mathrm{P}]} \\
{[\mathrm{G} 6 \mathrm{P}]}\end{array}$ & 0.31 & 0.32 & 0.23 \\
\hline$\frac{[\mathrm{FDP}][\mathrm{ADP}]}{[\mathrm{F} 6 \mathrm{P}][\mathrm{ATP}]}$ & 0.08 & 0.48 & 0.07 \\
\hline$\frac{[\mathrm{DHAP}][\mathrm{GA} 3 \mathrm{P}]}{[\mathrm{FDP}]} \times 10^{5}$ & 1.2 & 5.3 & 0.49 \\
\hline $\begin{array}{l}{[\mathrm{GA} 3 \mathrm{P}]} \\
{[\mathrm{DHAP}]}\end{array}$ & 0.81 & 0.57 & 0.47 \\
\hline$\frac{[\mathrm{GA} 3 \mathrm{P}]^{2}}{[\mathrm{FDP}]} \times 10^{5}$ & 0.95 & 0.22 & 0.13 \\
\hline$\frac{[3 \mathrm{PG}][\mathrm{NADH}][\mathrm{ATP}]}{[\mathrm{GA} 3 \mathrm{P}][\mathrm{NAD}][\mathrm{Pi}][\mathrm{ADP}]}$ & 0.56 & 0.22 & 0.13 \\
\hline$[2 \mathrm{PG}]$ & 0.36 & 0.50 & 0.45 \\
\hline$\left[\begin{array}{l}{[\mathrm{PEP}]} \\
{[2 \mathrm{PG}]}\end{array}\right.$ & 6.7 & 1.0 & 6.2 \\
\hline$\frac{[\mathrm{Pyr}][\mathrm{ATP}]}{[\mathrm{PEP}][\mathrm{ADP}]}$ & 4.5 & 23.9 & 10.2 \\
\hline$\frac{[\mathrm{NAD}]}{[\mathrm{NADH}]} \times 10^{-2}$ & 7.2 & 7.6 & 25.7 \\
\hline
\end{tabular}


Therefore, the term 'phosphorylase' in the following discussion really represents 'phosphorylase + phosphoglucomutase' (see ref. 16 for further discussion). For consistency with the previous paper (16), all glycolytic steps were in a quasi-equilibrium state, except for the three steps catalyzed by phosphorylase, phosphofructokinase and pyruvate kinase, because the apparent mass action ratios of these glycolytic steps did not much alter the equilibrium constants of the respective reactions. Both fertilization and db-cAMP treatment caused increases in the mass action ratios for reactions catalysed by these three rate limiting enzymes; that is, db-cAMP activates all three reaction steps in unfertilized eggs.

Since db-cAMP probably activates these enzymes by different mechanisms, the mass action ratios (Kapp) of these steps were examined in detail (Table 5). The optimal concentration of db-cAMP for activation of phosphorylase was $5 \mathrm{mM}$, while that for both phosphofructokinase and pyruvate kinase was $10 \mathrm{mM}$. Prolonged incubation depressed Kapp for phosphorylase, while the Kapp for the other two enzymes practically remained unchanged (data not shown). These results may reflect differences in the activation mechanism. Phosphorylase is activated through activation of its kinase (12).

TABLE 5. PARAMETERS OF THREE RATE LIMITING STEPS IN GLYCOLYSIS AS A FUNCTION OF db-CAMP CONCENTRATION

\begin{tabular}{lccccc}
\hline & \multicolumn{5}{c}{ db-cAMP concentration $(\mathrm{mM})$} \\
\cline { 2 - 6 } & 0 & 1 & 5 & 10 & 50 \\
\hline $\begin{array}{l}\text { Phosphorylase } \\
\quad \text { Kapp }\end{array}$ & 2.4 & 4.2 & 7.6 & 6.1 & 4.4 \\
$\begin{array}{l}\text { Phosphofructokinase } \\
\quad \text { P potential }\end{array}$ & 1.57 & 1.47 & 1.58 & 1.65 & 1.65 \\
$\quad$ Kapp & 0.08 & 0.12 & 0.21 & 0.48 & 0.53 \\
$\begin{array}{l}\text { Pyruvate kinase } \\
\text { FDPa }\end{array}$ & 3.2 & 6.8 & 31.4 & 52.4 & 50.6 \\
$\quad$ Kapp & 4.5 & 4.2 & 16.8 & 23.9 & 21.6 \\
\hline
\end{tabular}

$a$ n moles $/ 10^{6}$ eggs.

Phosphofructokinase activity in eggs increases after fertilization with a close relationship to the decline in phosphate potential (16) or to elevation of cAMP level (1). In this experiment, the increase in phosphofructokinase activity was independent of the phosphate potential (Table 4). Therefore, the enzyme is activated directly by the action of db-cAMP penetrating into unfertilized eggs.

The pyruvate kinase activity of the db-cAMP-treated eggs was found to increase with increases in fructose 1, 6-bisphosphate content (Table 5). Hence, the main activator is fructose bisphosphate, the product of phosphofructokinase. Thus, db-cAMP independently activates both phosphorylase kinase and phosphofructokinase, resulting in activation of glycolysis.

Although several cell functions are known to be affected by cAMP (10), glycolysis is the only system activated by db-cAMP in the present experiment. A possibility that the activation effect of $\mathrm{db}$-cAMP might be mediated by $\mathrm{Ca}$ ions penetrating into eggs seemed unfeasible, because the influx of $\mathrm{Ca}$ ions was not triggered by db-cAMP and because db-cAMP treatment supports the above conclusion, since an increase in intracellular free $\mathrm{Ca}$ ions induces discharge of the contents of cortical granules 
(15). Therefore, the level of $\mathrm{Ca}$ ions in eggs does not change when they are immersed in db-cAMP-containing sea water.

The penetration of db-cAMP was not demonstrated directly because of interference by extracellular db-cAMP. However, since enzymes which were under control of cAMP were activated by db-cAMP treatment, changes in metabolic activities observed in db-cAMP-treated eggs were probably caused by the action of db-cAMP penetrating into eggs.

The fact that db-cAMP treatment caused accumulation of pyruvate ( + lactate) without activating respiration indicates that a poor supply of substrates is not the cause of the lower rate of respiration in unfertilized eggs. Hence, stimulation of respiration on fertilization may be caused by other mechanisms than an increased supply of substrates.

It is concluded that an increase in cAMP level in eggs only participates in the activation of glycolysis upon fertilization. On the other hand, it has been found that $\mathrm{Ca}$ ionophore A23187 causes an activation of many cell functions (13). It has also been suggested that mitochondrial oxygen consumption is enhanced with increased $\mathrm{Ca}^{2+}(6)$. An increase of free $\mathrm{Ca}$ ions is probably responsible for the activation of more cell functions than the elevation of cAMP content upon fertilization.

Acknowledgment. A part of this work was supported by the Grant No. 134061 from the Ministry of Education, Japan.

\section{REFERENCES}

1. Asami, K., A. Fujiwara, R.L. Shoger and I. Yasumasu. Reversal of ATP inhibition of phosphofructokinase by nucleotides and phosphate as a possible regulatory mechanism of sea urchin egg glycolysis. Cell Struct. Funct. 1, 43-50, 1975

2. Chappel, J.R. The oxidation of citrate, isocitrate and cisaconitate by isolated mitochondria. Biochem. J. 90, 225-237, 1964

3. Fujiwara, A., K. Asami, R.L. Shoger and I. Yasumasu. Factors affecting the activity and the distribution of pyruvate kinase in sea urchin eggs. Submitted for publication

4. Haeckel, R., B. Hess, W. Lauterborn and K.-H. Wuster. Purification and allosteric properties of yeast pyruvate kinase. Hoppe-Seyler's Z. Physiol. Chem. 349, 699-714, 1968

5. Lowry, O.H., N.J. Rosebrough, A.L. Farr and R.J. Randall. Protein measurement with the Folin phenol reagent. J. Biol. Chem. 193, 265-275, 1951

6. Nakazawa, T., K. Asami, R.L. Shoger, A. Fujiwara and I. Yasumasu. $\mathrm{Ca}^{2+}$ uptake, $\mathrm{H}^{+}$ ejection and respiration in sea urchin eggs on fertilization. Exp. Cell Res. 63, 143-149, 1970

7. Nath, J., and L.I. RebHun. Studies on cyclic AMP levels and phosphodiesterase activity in developing sea urchin eggs. Effects of puromycin, 6-dimethylamino purine and $\mathrm{N}^{6}, \mathrm{O}^{2}$-dibutyrul cAMP in sea urchin eggs. Exp. Cell Res. 83, 73-78, 1973

8. Ohnishi, T., and M. Sugiyama. Polarographic studies of oxygen uptake of sea urchin egg. Embryologia 8, 79—88, 1963

9. Ozawa, E., and S. EBashi. Requirements of $\mathrm{Ca}$ ion for the stimulating effect of cyclic $3^{\prime}, 5^{\prime}$-AMP on muscle phosphorylase $b$ kinase. J. Biochem. (Tokyo) 62, 285-286, 1967

10. Robinson, G.A., R.W. Butcher and E.W. Sutherland. Cyclic AMP. Ann. Rev. Biochem. 37, 149-179, 1968

11. Rudolph, S.A., and P. Greengard. Regulation of protein phosphorlyation and membrane permeability by $\beta$-adrenergic agents and cyclic adenosine $3^{\prime}, 5^{\prime}$-monophosphate on the avian erythrocyte. J. Biol. Chem. 249, 5684-4687, 1974

12. Shoger, R.L., K. Asami, I. Yasumasu and A. Fujiwara. Activation of phosphorylase in sea urchin eggs by $\mathrm{Ca}^{2+}$ and cyclic $3^{\prime}, 5^{\prime}$-AMP. A possible mechanism of the regulation of its activity at fertilization. Exp. Cell Res. 82, 375-382, 1973 
13. Steinhardt, R.A., and D. Epel. Activation of sea-urchin eggs by a calcium ionophore. Proc. Natl. Acad. Sci. USA 71, 1915-1919, 1974

14. Tada, M., M.A. Kirchberger, D.I. Repke and A.M. Katz. The stimulation of calcium transport in cardiac sarcoplasmic reticulum by adenosine $3^{\prime}, 5^{\prime}$-monophosphate-dependent protein kinase. J. Biol. Chem. 249, 6174-6180, 1974

15. VACQUIER, V.D. The isolation of intact cortical granules from sea urchin eggs: calcium ions trigger granule discharge. Dev. Biol. 43, 62-74, 1975

16. Yasumasu, I., K. Asami, R.L. Shoger and A. Fujiwara. Glycolysis of sea urchin eggs. Rate limiting steps and activation at fertilization. Exp. Cell Res. 80, 361-371, 1973

17. Yasumasu, I., A. Fujiwara and K. Ishida. Periodic change in the content of adenosine $3^{\prime}, 5^{\prime}$ cyclic monophosphate with close relation to the cycle of cleavage in the sea urchin egg. Biochem. Biophys. Res. Commun. 54, 628-632, 1973 